Original Research Article

\title{
An observational study on the prescription pattern of antihypertensive drugs in a private health care centre, Chennai
}

\author{
Nithya Panneerselvam ${ }^{1} *$, Hemanthkumar Shanmugam ${ }^{2}$, Revathi Somasundaram ${ }^{1}$, \\ Ummul Khaier ${ }^{1}$
}

Department of Pharmacology,

${ }^{1}$ Meenakshi Medical College

and Hospital, Meenakshi

Academy of Higher Education and Research (Deemed to be university), Kanchipuram,

${ }^{2}$ Meenakshi Ammal Dental

College and Hospital,

Meenakshi Academy of Higher

Education and Research

(Deemed to be university),

Chennai, Tamil Nadu, India

Received: 26 June 2019

Revised: 10 August 2019

Accepted: 29 August 2019

\section{*Correspondence to:}

Dr. Nithya Panneerselvam,

Email: nithi_josan@yahoo.co.in

Copyright: (C) the author(s), publisher and licensee Medip Academy. This is an openaccess article distributed under the terms of the Creative Commons Attribution NonCommercial License, which permits unrestricted noncommercial use, distribution, and reproduction in any medium, provided the original

\begin{abstract}
Background: Hypertension is a public health problem worldwide. Elevated systolic blood pressure $\geq 140 \mathrm{~mm} \mathrm{Hg}$ or diastolic blood pressure $\geq 90 \mathrm{mmHg}$ are defined as Hypertension. The choice of an antihypertensive drug is based on its efficacy, side-effects, effects on other systems and cost. The objective of this study is to evaluate the prescription pattern of antihypertensive drugs in a private health care centre.

Methods: A retrospective observational study was carried out in the out-patient department of a private health care centre, Chennai from November 2018 to December 2018.

Results: In the present study, 104 prescriptions were selected based on the inclusion criteria. In which $62(59.61 \%)$ were males and $42(40.38 \%)$ were females. Prescriptions belonging to age group of <40 years were $11(10.57 \%)$, $40-59$ years were $48(46.15 \%)$ and $>60$ years were $45(43.26 \%)$. Monotherapy was received by 62 hypertensive patients and as combination therapy by 42 patients.

Conclusions: Even though the prescription pattern of antihypertensive drugs in this study complied with the recommended guidelines, clinicians should always be vigilant and consider change of regimen whenever necessary.
\end{abstract}

Keywords: Antihypertensive drugs, Prescription pattern, Monotherapy, Combination therapy

\section{INTRODUCTION}

Hypertension is a public health problem worldwide and contributes to the development of non-communicable diseases, especially cardiovascular disease. ${ }^{1,2}$ Elevated systolic blood pressure $\geq 140 \mathrm{~mm} \mathrm{Hg}$ or diastolic blood pressure $\geq 90 \mathrm{~mm} \mathrm{Hg}$ are defined as Hypertension. ${ }^{3}$ The prevalence of hypertension increases with age. Increasing the awareness and diagnosis of hypertension and better control of blood pressure with appropriate treatment protocol are the most important initiatives taken to reduce cardiovascular morbidity and mortality. ${ }^{4}$ The most prominent evidence based guideline for the management of hypertension was framed by the Seventh Report of the Joint National Committee on the Detection, Evaluation, and Treatment of High Blood Pressure (JNC VII). ${ }^{5}$ Efforts for achieving blood pressure (BP) control should be intensified using recommended guidelines. Assessing individuals with hypertension for BP control and auditing antihypertensive precription patterns can play key roles in the reducing the burden of hypertension. The choice of an antihypertensive drug is based on its efficacy, sideeffects, effects on other systems and cost. Accordingly, there is always a need to survey the pattern of antihypertensive drugs usage for its rationality and 
whether they are in concordance with current guidelines for treatment of hypertension. ${ }^{6}$ Hence, the present study was done to study the current prescription trends of antihypertensive drugs by consultants in India.

\section{METHODS}

A retrospective observational study was carried out in the out-patient department of a S.S Hospital and Diabetic Health Care Centre, Chennai from November 2018 to December 2018. Prescriptions of hypertensive patients who attended the OPD without any co-morbid illness were included in the study. Duration of hypertension of greater than 4 years were also fixed in the inclusion criteria. Prescriptions of patients with hypertension due to secondary cause, pregnancy induced hypertension were excluded from the study. Prescriptions containing incomplete data of frequency, dose, duration of the drugs and patients who were suggested for life style modifications were not considered for the study. Descriptive statistics was used and values were expressed in percentage.

\section{RESULTS}

In the present study, 104 prescriptions were selected based on the inclusion criteria. In which $62(59.61 \%)$ were males and $42(40.38 \%)$ were females. Prescriptions belonging to age group of $<40$ years were $11(10.57 \%)$, 40 - 59 years were $48(46.15 \%)$ and $>60$ years were 45 (43.26\%) (Table 1). Monotherapy was received by 62 hypertensive patients and as combination therapy by 42 patients. Among the monotherapeutic agents, enalapril (22\%) and metoprolol (22\%) were the most commonly prescribed drugs followed by amlodipine (21\%), losartan $(18 \%)$, telmisartan $(3 \%)$, olmesartan $(5 \%)$, atenolol $(2 \%)$, ramipril (3\%), nifedipine( $2 \%)$ and cilnidipine (2\%) as shown in Figure 1. When these agents were classified based on their groups, there was almost equal distribution of each class. Angiotensin receptor blockers (ARBs) (26\%), angiotensin converting enzymes inhibitors (ACEIs) (26\%), calcium channel blockers (CCBs) $(24 \%)$ and beta blockers (24\%) (Figure 2). The most frequent combination therapy prescribed was amlodipine + atenolol (41\%) followed by ARBs + diuretic namely telmisartan + hydrochlorothiazide (24\%) and losartan + hydrochlorothiazide (14\%). Equal distribution of combinations of enalapril + amlodipine $(7 \%)$ and telmisartan + metoprolol $(7 \%)$ was observed as shown in Figure 3.

Table 1: Demographic characteristics $(n=104)$.

\begin{tabular}{|ll|}
\hline Characteristics & $\mathbf{N}(\%)$ \\
\hline Age group (yrs) & \\
\hline$<40$ & $11(10.57)$ \\
\hline $40-59$ & $48(46.15)$ \\
\hline$>60$ & $45(43.26)$ \\
\hline Gender & \\
\hline Male & $62(59.61)$ \\
\hline Female & $42(40.38)$ \\
\hline
\end{tabular}

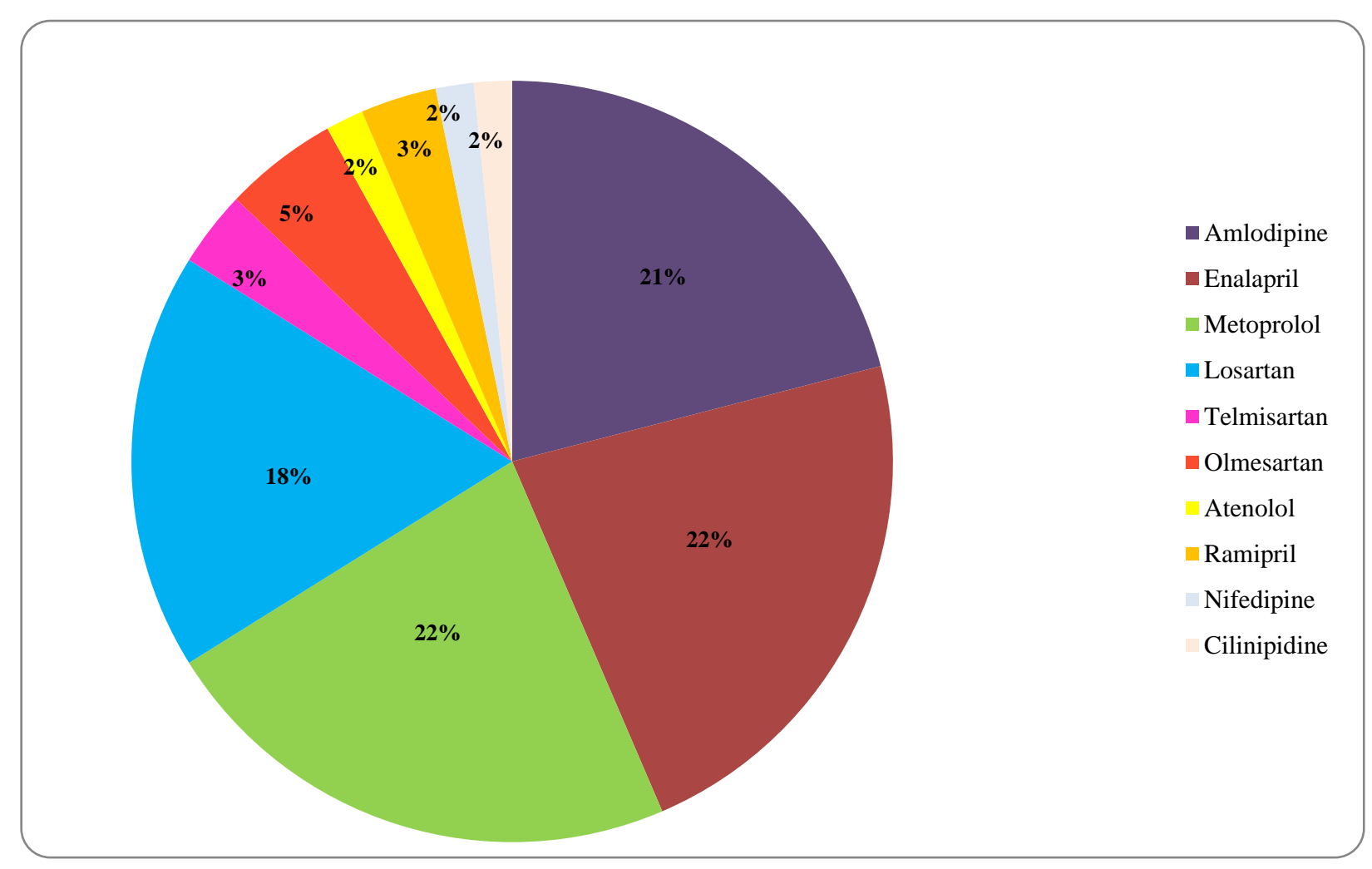

Figure 1: Drug utilization pattern of monotherapeutic agents in hypertension. 


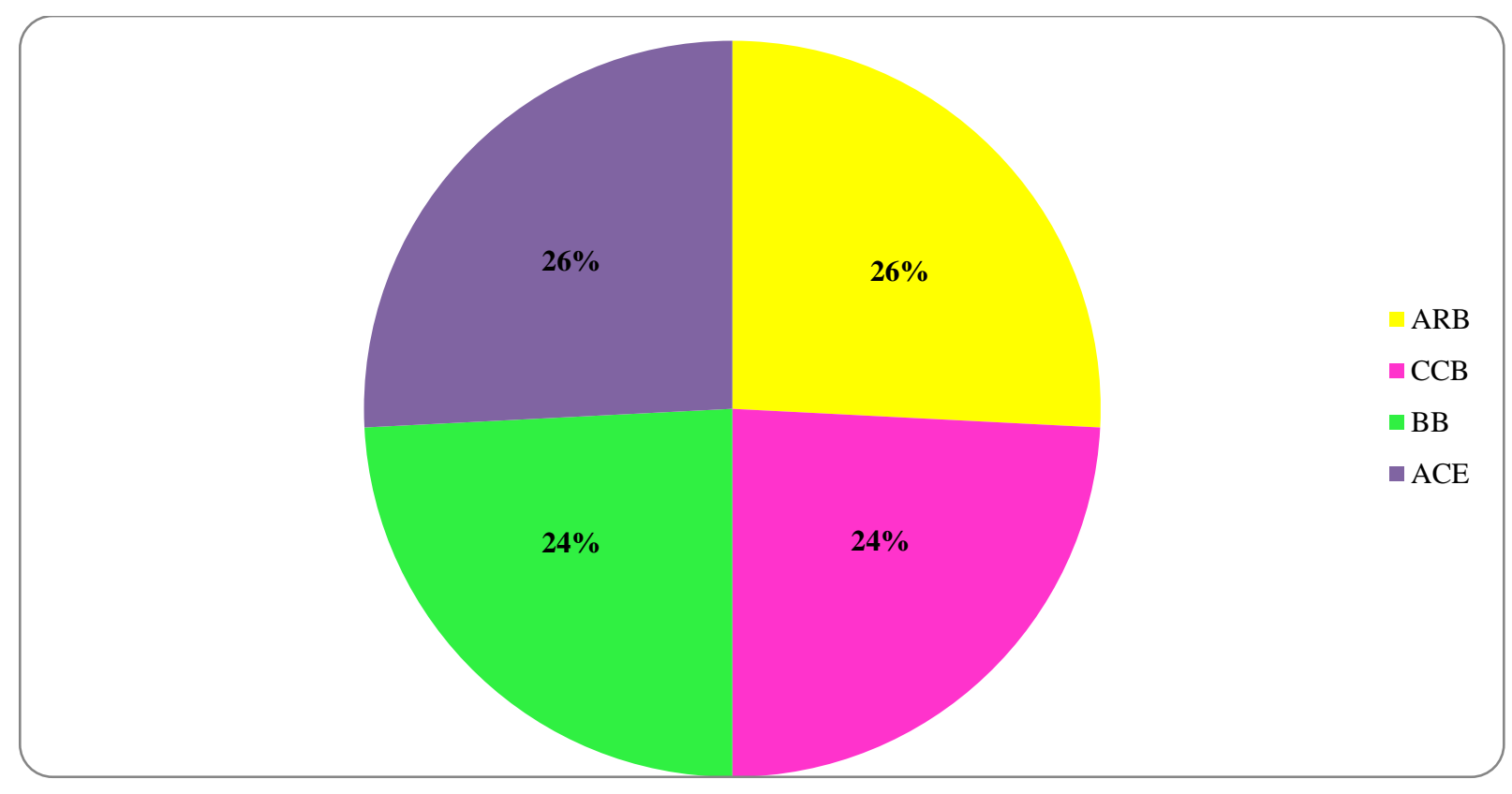

Figure 2: Percentage of antihypertensive prescribed based on classification.

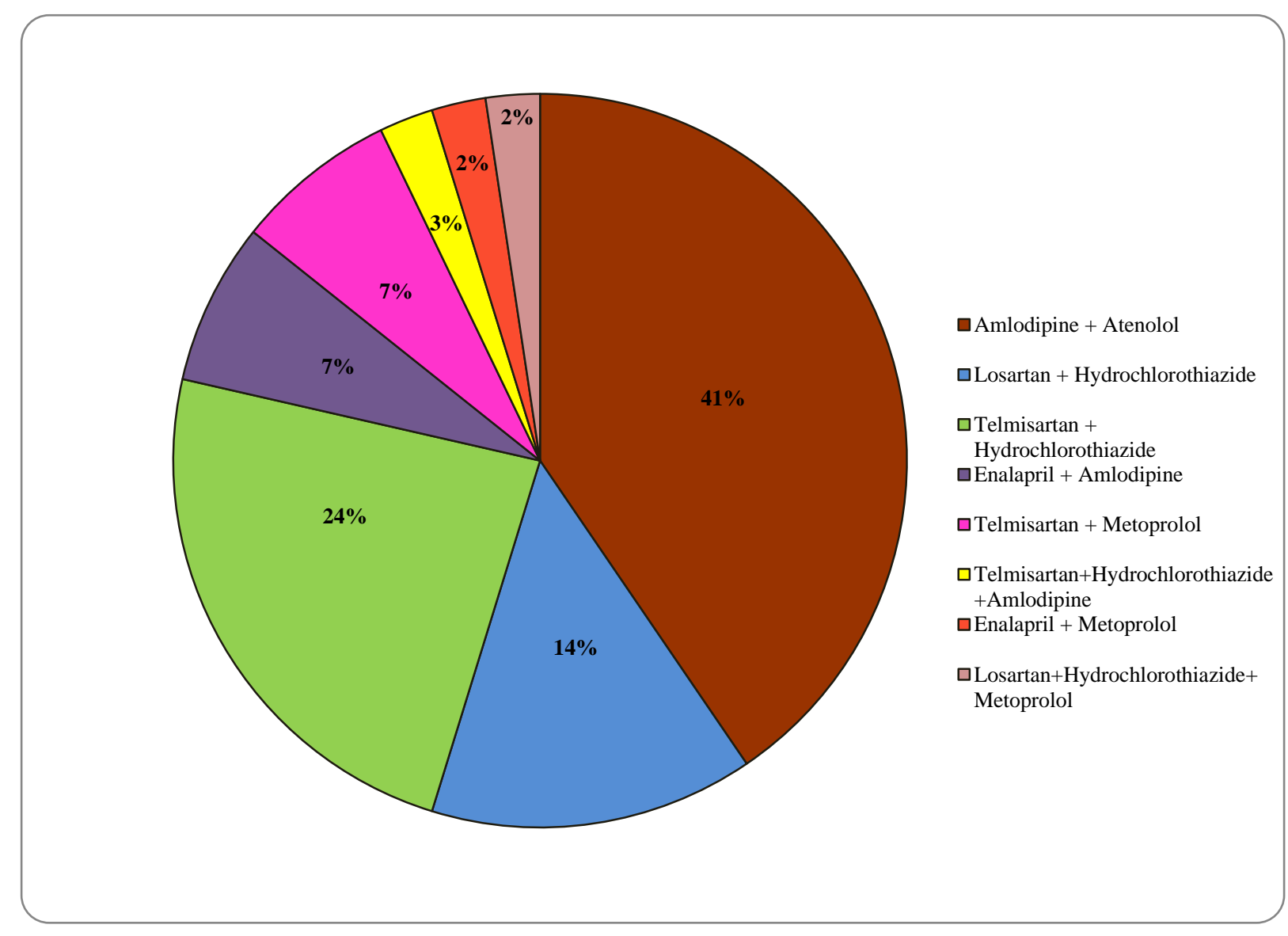

Figure 3: Drug utilization pattern of combination regimens in hypertension.

\section{DISCUSSION}

In this study unsurprisingly, the majority of hypertensive patients were above the age group of 40 years, this finding is comparable to previous studies related to hypertension. ${ }^{7}$ Hypertension is more prevalent among older individuals due to increased arterial and arteriolar wall stiffness, increased responsiveness to sympathetic nervous stimuli, decreased baroreceptor sensitivity and 
altered renal and sodium metabolism associated with aging. 8,9

The present study observed the prevalence of hypertension more common in males $(59.61 \%)$ when compared to females $(40.38 \%)$ which was in contrast to the previous study by Kuchake et al. ${ }^{10}$ Findings of the present study were different from that previous literatures stating combination therapy was commonly prescribed than monotherapy. ${ }^{11}$

Though, JNC VII and Indian hypertension guidelines II (2007) recommend thiazides as initial therapy either alone or in combination with other classes of antihypertensive drugs, the NICE guidelines of UK recommend $\mathrm{ACEI}$ or a low-cost $\mathrm{ARB}$ for hypertensive patients aged under 55 years and a CCB to people aged over 55 years. ${ }^{12-14}$ Our findings in the present study are suggestive of ACE and ARB antihypertensive drugs as first line of monotherapeutic agents with is comparable with NICE guidelines. But in the present study there was no role of diuretics as monotherapeutic agents.

Most frequent use of CCBs in this study may be due to their established efficacy and better tolerance. Utilization of ACEIs and ARBs in a greater extent might be because of physicians' perceptions that ACEIs and ARBs have better control on blood pressure, its cardiovascular \& renal protection and fewer side effects compared to diuretics. The decreasing use of diuretics, which is reflected in our study may be explained by physician misperceptions that diuretics are less effective, less safe. ${ }^{15}$ $\mathrm{BBs}$ are considered as one of the first line antihypertensive drug classes, Some prefer to use BBs only in patients with compelling cardiac indications for them or as add on agents in those with uncontrolled or resistant hypertension. ${ }^{16}$ Use of beta blockers (BB) as monotherapy has contributed around $24 \%$.

JNC-7 doesn't give clear guidelines as to which antihypertensive drug combinations should be preferred. ${ }^{3}$ Indian hypertension guidelines-II recommend the combination of one out of the two groups viz. drugs acting on 'RAS (ACEI/ARB) or BB' with 'CCB or thiazide diuretic' but discourages the use of combination of diuretics and BBs for the fear of new-onset diabetes mellitus. It further recommends use of combination of $\mathrm{ACEI} / \mathrm{ARB}+\mathrm{CCB}+$ thiazide diuretic when 3 antihypertensive drugs are needed. ${ }^{3}$ In our present study, the combinations had adhered to the above guideline of 2 drug having amlodipine + atenolol (CCB \& BB), telmisartan + hydrochlorothiazide (ARB and thiazide diuretic), enalapril + amlodipine (ACE \& CCB) and 3 drug therapy having telmisartan + hydrochlorothiazide tamlodipine (ARB and CCB and thiazide diuretic). There was also not a single combination of $\mathrm{BB}$ and diuretic in the present study.

In the present study the physicians had strictly followed and complied with Indian hypertension guidelines II on prescribing the antihypertensive drugs. This study has provided an insight about the prescription patterns of antihypertensive drugs with respect to the blood pressure.

\section{CONCLUSION}

Even though the prescription pattern of antihypertensive drugs in this study complied with the recommended guidelines, Clinicians should always be vigilant and consider regimen changes if the contemporary regimens do not bring changes in blood pressure. Therapeutic modifications could always bring about an improvement in BP. Further studies from time to time are required to study the drug utilization pattern of antihypertensive drugs. Furthermore, physicians should be sensitized to adhere to the standard treatment guidelines.

\section{ACKNOWLEDGEMENTS}

Authors would like to express their sincere thanks to the private health care centre for the access to the prescriptions.

\section{Funding: No funding sources}

Conflict of interest: None declared

Ethical approval: The study was approved by the Institutional Ethics Committee

\section{REFERENCES}

1. Wolf-Maier K, Cooper RS, Banegas JR, Giampaoli $\mathrm{S}$, Hense HW, Joffres $\mathrm{M}$, et al. Hypertension prevalence and blood pressure levels in 6 European countries, Canada, and the United States. JAMA. 2003;289:2363-9.

2. Muna WF. Cardiovascular disorders in Africa. World Health Stat Q. 1993;46:125-33.

3. Chobanian AV, Bakris GL, Black HR, Cushman WC, Green LA, Izzo JL, et al. Seventh report of the Joint National Committee on Prevention, Detection, Evaluation, and Treatment of High Blood Pressure. Hypertension. 2003;42(6):1206-52.

4. DiPiro JT, Talbert RL, Yee GC, Matzke GR, Wells BG, Posey LM, et al. Book Review: Pharmacotherapy: A Pathophysiologic Approach, 7th Edition. Annals of Pharmacotherapy. 2009:43(2):395.

5. Hedley AA, Ogden CL, Johnson CL, Carroll MD, Curtin LR, Flegal KM. Prevalence of overweight and obesity among US children, adolescents, and adults. JAMA. 2004;291(23):2847-50.

6. Pai PG, Shenoy J, Sanji N. Prescribing patterns of antihypertensive drugs in a South Indian tertiary care hospital. Drug Invent Today. 2011;3(4):38-40.

7. Busari OA, Oluyombo R, Fasae AJ, Gabriel EO, Ayodele LM, Agboola SM, et al. Prescribing pattern and utilization of antihypertensive drugs and blood pressure control in adults patients with systemic hypertension in a rural tertiary hospital in Nigeria. Am J Inter Med. 2014;2(6):144-9. 
8. Pinto E. Blood pressure and aging. Postgrad Med J. 2007;83(976):109-14.

9. Weber MA, Neutel JM, Cheung DG. Hypertension in the aged: a pathophysiologic basis for treatment. Am J Cardiol. 1989;63(16):25-32.

10. Kuchake VG, Maheshwari OD, Patel RC. Prescription Pattern of Antihypertensive Drugs in Uncomplicated Hypertensive Patients at Teaching Hospital. Indian J Pharm Pract. 2009;2(2):74-80.

11. Sharma AK, Dahiya N, Kairi JK, Bharati SM. Prescription patterns of antihypertensive drugs in a tertiary care hospital in India. Int $\mathrm{J}$ Basic Clin Pharmacol. 2015;4(1):55-9.

12. Chobanian AV, Bakris GL, Black HR, Cushman WC, Green LA, Izzo JL, et al. Seventh report of the Joint National Committee on Prevention, Detection, Evaluation, and Treatment of High Blood Pressure. Hypertension. 2003;42(6):1206-52.

13. Shah S, Anand P, Maiya M, Mukherjee S, Munjal YP, Wander GS, et al. Indian hypertension guideline 2007. In: Munjal YP, editor. Postgraduate Medicine (Recent Advances in Medicine). New Delhi: The Association of Physicians of India and Indian College of Physicians, Ajanta Offset and Packaging Ltd.; 2007:21:315-25

14. National Clinical Guideline Centre (UK). Hypertension: the Clinical Management of Primary Hypertension in Adults: update of Clinical Guidelines 18 and 34. (NICE Clinical Guidelines, No. 127.). London: Royal College of Physicians (UK); 2011

15. Rochefort CM, Morlec J, Tamblyn RM. What differentiates primary care physicians who predominantly prescribe diuretics for treating mild to moderate hypertension from those who do not? A comparative qualitative study. BMC Fam Pract. 2012;13:9.

16. Che Q, Schreiber MJ, Rafey MA. Beta-blockers for hypertension: are they going out of style? Cleve Clin J Med. 2009;76(9):533-42.

Cite this article as: Panneerselvam N, Shanmugam H, Somasundaram R, Khaier U. An observational study on the prescription pattern of antihypertensive drugs in a private health care centre, Chennai. Int $\mathbf{J}$ Basic Clin Pharmacol 2019;8:2232-6. 